\title{
\CLINICAL VIGNetTE
}

\section{Nonroutine use of 2-dimensional speckle tracking echocardiography and fatigue} assessment to monitor the effects of therapeutic venesections in a patient with newly diagnosed hereditary hemochromatosis

\author{
Michał Świątczak¹, Katarzyna Sikorska², Grzegorz Raczak¹, Ludmiła Daniłowicz-Szymanowicz' \\ 1 2nd Department of Cardiology and Electrotherapy, Medical University of Gdańsk, Gdańsk, Poland \\ 2 Department of Tropical Medicine and Epidemiology, Medical University of Gdańsk, Gdańsk, Poland
}

\author{
Correspondence to: \\ Ludmiła Daniłowicz-Szymanowicz, \\ MD, PhD, 2nd Department \\ of Cardiology, Medical University \\ of Gdańsk, ul. Dębinki 7, \\ 80-211 Gdańsk, Poland, phone: \\ +48583493910, email: \\ ludwik@gumed.edu.pl \\ Received: April 23, 2020. \\ Revision accepted: May 8, 2020 \\ Published online: May 12, 2020. \\ Kardiol Pol. 2020; 78 (7-8): 786-787 \\ doi:10.33963/KP.15357 \\ Copyright by the Author(s), 2020
}

Hereditary hemochromatosis $(\mathrm{HH})$ is a genetic disease which, in over $80 \%$ of cases, is related to the C282Y mutation in the HFE gene. This condition leads to excessive iron absorption and accumulation in different organs, including the heart, and ultimately their damage. The process of cardiac involvement is typically slow and extended in time. Incremental accumulation of iron in cardiomyocytes induces oxidative stress and causes tissue damage which eventually results in heart failure, always associated with a bad prognosis. ${ }^{1}$ Although therapy reducing overall iron level may reduce cardiac lesions, it is crucial to prevent their progress by the upfront treatment at the preclinical phase of the disease. However, during the early phase of the disease, when patients do not present severe abnormalities such as increased serum iron parameters and severe symptoms of impairment of other organs, heart damage may be even overlooked due to the lack of evident signs of cardiac dysfunction in the routine cardiac screening. The most important diagnostic tools to detect myocardial infiltration are cardiac magnetic resonance (CMR) and echocardiography; however, despite the indisputable value of $C M R,{ }^{2}$ this is not a first-line diagnostic technique in the daily clinical practice. Echocardiography, as a widely available modality, with special attention to 2-dimensional speckle tracking echocardiography (2D STE), allows the detection of discrete abnormalities of the heart, ${ }^{3}$ including patients with $\mathrm{HH}$ as we showed in our previous study. ${ }^{4}$

We present the case of a 42-year-old man with newly diagnosed $\mathrm{HH}$ (C282Y / H63D mutation in the HFE gene) with a nonroutine use of 2D STE and authorial fatigue assessment scheme in the monitoring of the effects of venesection treatment. Echocardiography was performed at the time of diagnosis and after 6 months from venesection therapy. The Fatigue Assessment Scale ${ }^{5}$ (FAS; assesses the overall fatigue), the Chalder Fatigue Scale (CFQ; assesses fatigue in the last month), and the Fatigue Severity Scale (FSS; assesses fatigue in the last week) were carried out before and up to 2 weeks after each venesection.

During the 6-month follow-up, the patient had 6 venesections, achieving an overall reduction of ferritin level from 663 to $175 \mathrm{ng} / \mathrm{ml}$ (Supplementary material, Table S1). Echocardiography was performed using the GE VIVID E95 ultrasound system (GE Ultrasound, Horten, Norway) equipped with phased-array transducer (M5S). For each view, 3 consecutive cardiac cycles were recorded during quiet respiration; gray scale recordings were optimized for left ventricular (LV) evaluation at a frame rate of 50 to $80 \mathrm{frames} / \mathrm{s}$; echocardiograms were stored digitally, and further offline analysis was performed using a commercial EchoPAC workstation (v201, GE Healthcare Horten, Norway). On 

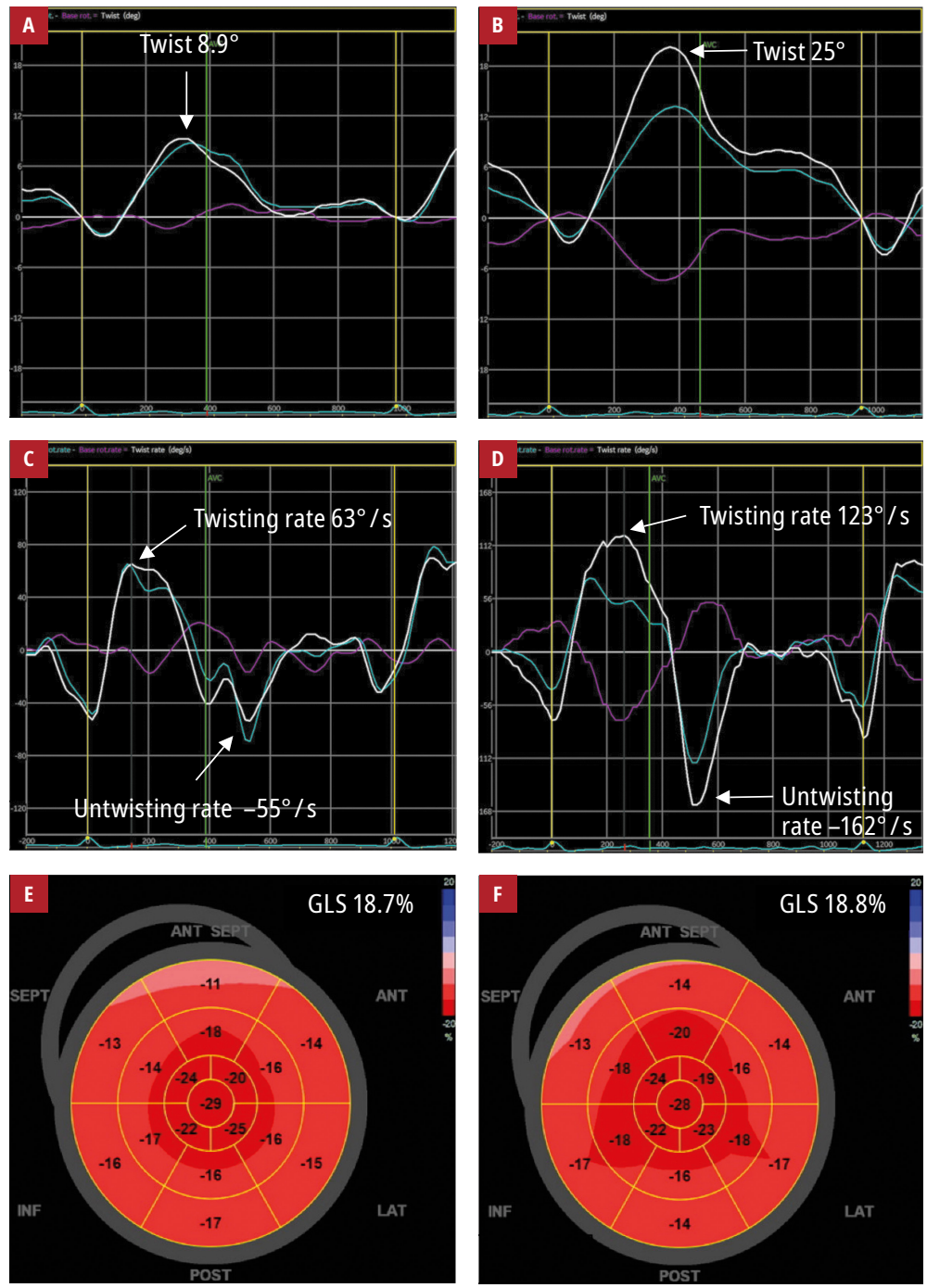

FIGURE 1 Two-dimensional speckle tracking echocardiography of a 42-year-old man with early diagnosed $\mathrm{HH}$ before (A, C, E) and after 6 months (B, D, F) of venesections. Twist ( $\mathbf{A}$ and $\mathbf{B})$, left ventricular twisting rate, and left ventricular untwisting rate ( $\mathbf{C}$ and $\mathbf{D}$ ) increased significantly; there were no changes in global longitudinal strain which was at a lower level of normal (E and $\mathbf{F}$ ). the increase in LV rotation and the improvement in the quality of life in patients with near-normal resting echocardiography (except lower rotation and borderline GLS); however, rotation abnormalities could be symptomatic and, when corrected, paralleled by clinical improvement. All conclusions listed above require further observation in appropriate groups of patients with $\mathrm{HH}$, including hemodynamic parameters, such as natriuretic peptides.

\section{SUPPLEMENTARY MATERIAL}

Supplementary material is available at www.mp.pl/kardiologiapolska.

\section{ARTICLE INFORMATION}

\section{CONFLICT OF INTEREST None declared.}

OPEN ACCESS This is an Open Access article distributed under the terms of the Creative Commons Attribution-NonCommercial-NoDerivatives 4.0 International License (CC BY-NC-ND 4.0), allowing third parties to download articles and share them with others, provided the original work is properly cited, not changed in any way, distributed under the same license, and used for noncommercial purposes only. For commercial use, please contact the journal office at kardiologiapolska@ptkardio.pl.

HOW TO CITE Świątczak M, Sikorska K, Raczak G, Daniłowicz-Szymanowicz L. Nonroutine use of 2-dimensional speckle tracking echocardiography and fatigue assessment to monitor the effects of therapeutic venesections in a patient with newly diagnosed hereditary hemochromatosis. Kardiol Pol. 2020; 78: 786-787. doi:10.33963/KP.15357

\section{REFERENCES}

1 Gulati V, Harikrishnan P, Palaniswamy C, et al. Cardiac involvement in hemochromatosis. Cardiol Rev. 2014; 22: 56-68.

2 Kwiatkowska J, Meyer-Szary J, Bazgier M, et al. Left ventricular volumes and function affected by myocardial fibrosis in patients with Duchenne and Becker muscular dystrophies: a preliminary magnetic resonance study. Kardiol Pol. 2020; 78: 331-334.

3 Mielczarek A, Kasprzak JD, Lipiec P, et al. Quantitative assessment of the rotation and twist of the left ventricle during dobutamine stress echocardiography: a comparison of patients with and without significant coronary artery disease. Kardiol Pol. 2019; 77: 696-702.

4 Rozwadowska K, Daniłowicz-Szymanowicz L, Fijałkowski M, et al. Can two-dimensional speckle tracking echocardiography be useful for left ventricular assessment in the early stages of hereditary haemochromatosis? Echocardiography. 2018; 35: 1772-1781.

5 De Vries J, Michielsen H, Van Heck GL, Drent M. Measuring fatigue in sarcoidosis: the Fatigue Assessment Scale (FAS). Br J Health Psychol. 2004; 9: 279-291. echocardiography, standard parameters were normal and did not change (Supplementary material, Table S2), while the parameters of rotation (twist, torsion, LV twisting rate, and LV untwisting rate) increased significantly; there were no changes in global longitudinal strain (GLS) which was at a lower level of normal (FIGURE 1A-1F). In the fatigue assessment, a gradual improvement was observed in all of the scales (in the FAS, reduction from 25 to 17 points, in the CFQ, from 12 to 5 points, in the FSS from 37 to 13 points) with the most spectacular effect after the 4 th venesection (Supplementary material, Table S3).

Venesections significantly reduce the intensity of fatigue in patients with $\mathrm{HH}$, which may be estimated with the aforementioned scales. The effects of this treatment in case of myocardial function can be monitored by speckle tracking echocardiography, which allows us to discover subtle changes in the heart, but this is not a standard procedure. It is difficult to connect 